\title{
AUDITORIA EXTERNA COMO FERRAMENTA DE MELHORIA NA GESTÃO EMPRESARIAL DO SETOR FINANCEIRO
}

\section{ARTIGO ORIGINAL}

PINO, Ketelim Pereira ${ }^{1}$, MOURA, Elisa de Cassia Oliveira ${ }^{2}$, SILVA, Matheus Simas da ${ }^{3}$, ROBERTO, José Carlos Alves ${ }^{4}$, SERRA, Meg Rocha da Cunha ${ }^{5}$, LOPES, Nelânia Ferreira ${ }^{6}$

PINTO, Ketelim Pereira. Et al. Auditoria externa como ferramenta de melhoria na gestão empresarial do setor financeiro. Revista Científica Multidisciplinar Núcleo do Conhecimento. Ano 06, Ed. 11, Vol. 04, pp. 153-176. Novembro de 2021. ISSN: 2448-0959, Link de acesso: https://www.nucleodoconhecimento.com.br/contabilidade/setor-financeiro

\section{RESUMO}

Em um contexto de rápido crescimento, a expansão de novas empresas no mercado brasileiro, trouxe modelos de negócios mais robustos, que visam a mitigação de riscos que comprometem as operações, o que tornou necessário a adaptação dos processos gerenciais, principalmente no setor financeiro, levando a um controle maior nas

${ }^{1}$ Graduando do curso de Contabilidade.

${ }^{2}$ Graduanda do curso de Ciências Contábeis.

${ }^{3}$ Graduando do curso de Contabilidade.

${ }^{4}$ Orientador. Mestre em Engenharia de produção. Especialista Logística empresarial. Graduado em Administração com Ênfase em Marketing.

5 Orientadora. Mestra em Engenharia de Processos Industriais pela UFPA, especialista em Controladoria e Auditoria Contábil pelo Ciesa (2020), Graduada em Ciências Contábeis pelo Centro Universitário do Norte (2010). Graduada em Ciências Econômicas pelo Centro Universitário do Norte (2006).

${ }^{6}$ Orientadora. Especialista em Auditoria Contábil, Financeira e Tributaria e Graduada em Ciências Contábeis. 
atividades, processos e monitoramento, tendo em vista as possibilidades de riscos envolvendo falhas e fraudes. Neste cenário, tornaram-se essenciais as atividades desenvolvidas por equipes de auditoria externa a fim de atestar controles e averiguar se os processos da empresa estão condizentes com o que é esperado nos procedimentos e nas legislações permanentes. O que levantou o questionamento sobre: Quais os benefícios da auditoria externa para o funcionamento do setor financeiro? Sendo assim, este presente estudo tem como objetivo explanar os benefícios da adoção da auditoria externa para o funcionamento do setor financeiro, mostrando os instrumentos utilizados pelo auditor, e o impacto de um parecer para melhoria da gestão empresarial. Trata-se de uma revisão bibliográfica sistemática que tem como intuito demonstrar e servir de base para futuros trabalhos a serem desenvolvidos, o qual consolidou os resultados dos estudos anteriores sobre o tema e apresentou de forma organizada as contribuições alcançadas através dos trabalhos selecionados. Nos resultados foram destacadas as principais vantagens da auditoria externa para a gestão financeira das empresas. Concluindo que a auditoria externa, ao examinar, analisar, corrigir e certificar as demonstrações contábeis e financeiras de uma empresa, torna-se uma ferramenta de gestão de melhoria indispensável ao setor financeiro, para controlar as atividades de uma organização.

Palavras-chave: Auditoria externa, financeiro, gestão empresarial.

\section{INTRODUÇÃO}

Nas últimas décadas, houve um aumento considerável na criação de empresas no mercado brasileiro, sendo elaborado modelos de negócios em diferentes áreas de atividade. Estas empresas foram constituídas por micro e pequenos empreendimentos realizados por pessoas comuns que deixaram o emprego em busca de serem empreendedores, ou que, tendo em vista o alto nível de desemprego no país, decidiram criar sua própria fonte de recursos para driblar a situação econômica desfavorável.

Porém, muitas empresas não conseguem se destacar no mercado, acumulando prejuízos, enfrentando situações em que operam fora dos requerimentos exigidos e 
até mesmo encontrando fraudes em seus processos financeiros. Para isso, é importante a identificação de riscos onde não há controle interno e a busca da avaliação constante das ações de gerenciamento e da probabilidade da avaliação dos impactos que podem decorrer sobre os objetivos dos negócios ou serviços prestados.

Com a falta de transparência e confiabilidade de algumas instituições, e a crescente competitividade do mercado de negócios, estabeleceu-se a seguinte questão norteadora: Quais os benefícios da auditoria externa para o funcionamento do setor financeiro? Procurando esclarecer essa pergunta, o presente artigo busca demonstrar e enaltecer o papel e os benefícios da auditoria externa, principalmente para os gestores das organizações. Através do parecer do auditor os gestores poderão direcionar e gerir melhor seus colaboradores, principalmente na área financeira que trabalha diretamente com a liquidez da empresa.

Assim, este presente artigo tem como objetivo demonstrar de forma explicativa a importância da auditoria externa perante as empresas, principalmente no controle e direcionamento do setor financeiro, utilizando como metodologia a revisão bibliográfica de forma qualitativa. Esta pesquisa busca explanar quais técnicas são utilizadas e adotadas pelo auditor externo e como a auditoria externa influência nas futuras decisões dos gestores, e atividades do setor financeiro, apresentando a importância e a contribuição deste trabalho para as empresas, estudantes e áreas afins.

Espera-se com os resultados responder e esclarecer o quanto é crucial a adoção da auditoria externa para empresas que querem se manter competitivas e ter espaço no mercado, além de amplo investidores, ao incorporarem esse ramo de atividade no gerenciamento e controle interno.

\section{FUNDAMENTAÇÃO TEÓRICA}

Esta seção objetiva descrever a fundamentação teórica da pesquisa. De acordo com Sousa et al. (2021), esse embasamento trata dos estudos teóricos publicados, sendo 
essencial a apropriação do domínio da leitura, do conhecimento e da sistematização do material analisado por parte do pesquisador.

\subsection{DEFINIÇÃO DE AUDITORIA}

Segundo Sammour e Cintra (2019), o surgimento da auditoria se deu no ano de 1.314 na Inglaterra. Enquanto, no Brasil, o seu aparecimento ocorreu no fim da Guerra Mundial, com as instalações de multinacionais no país.

Com isso, a auditoria se consolidou fundamentada na necessidade de garantir a veracidade das informações oriundas das demonstrações e dos registros contábeis. Do Amaral e Bertegani (2018) relatam que a origem e a evolução da auditoria estão intimamente ligadas com a evolução das ciências contábeis.

Desta forma, Sammour e Cintra (2019) descrevem que a auditoria vem se desenvolvendo e se modificando de acordo com a evolução e as mudanças do mundo corporativo, cujo seu aparecimento foi de suma importância para o contexto empresarial, principalmente para os stakeholders que necessitavam de análises precisas para o real conhecimento dos resultados financeiros das entidades.

Juntamente com essas transformações, Ribeiro (2011) relata sobre o surgimento de vários órgãos, como a Comissão d e Valores Mobiliários (CVM), o Comitê de Pronunciamentos Contábeis (CPC), o Banco Central do Brasil (BCB), o Conselho Federal de Contabilidade (CFC) e o Instituto de Auditores Independentes do Brasil (Ibracon). Ademais, o autor relata mais alguns acontecimentos, no Brasil, que contribuíram para alterações nos processos envolvendo a contabilidade e a auditoria, como:

- A formação do Instituto dos Auditores Independentes do Brasil, incorporando em seu quadro: auditores, contadores e estudantes;

- A instituição da Lei n 11.638/2007 em 1ํ de janeiro de 2008;

- E o estabelecimento de mudanças nas regras contábeis por intermédio da Medida Provisória $n^{\circ}$ 449, de 3 de dezembro de 2008, visto a necessidade da 
adequação completa das regras contábeis praticadas no Brasil aos padrões internacionais de contabilidade e auditoria.

Apresentadas as principais mudanças ocorridas em nível global e nacional nas últimas décadas, constata-se que a auditoria tornou-se um processo fundamental para as grandes e médias empresas, e tem sido cada vez mais utilizada por novos segmentos de mercado e empresas de pequeno porte, com o intuito de prover veracidade, confiabilidade e melhoria nos processos das organizações.

Com isso, Carvalho (2019) afirma que a auditoria é a sistematização imparcial relatada com o intuito de avaliar em forma de consultoria, onde os dados serão transformados em relatórios que contribuirão para a gestão empresarial.

Nesse contexto, existem dois tipos de auditoria: auditoria externa e auditoria interna. A auditoria externa ou auditoria independente ocorre por meio da realização de serviços de profissionais qualificados, contratados por uma empresa externa, que visa emitir uma opinião independente baseada em normas técnicas sobre a conformidade ou não das demonstrações contábeis. Assim, segundo Sammour e Cintra (2019), o objetivo desta é investigar possíveis erros ou fraudes e apresentá-los em forma de relatórios, sugerindo soluções.

\subsubsection{AUDITORIA INDEPENDENTE DAS DEMONSTRAÇÕES CONTÁBEIS}

A Auditoria independente da demonstração contábil visa atestar se as referências fornecidas pela empresa são coerentes, confiáveis e seguras, conforme Leitão et al. (2018) afirmam, na qual o auditor irá aplicar técnicas e testes para exprimir relatórios baseados na real situação da empresa. E é através destes relatórios que o setor financeiro de uma organização pode usufruir de muitos benefícios advindos da implantação de auditorias externas para melhoria dos fluxos e processos.

Logo abaixo é possível observar as principais características de uma auditoria externa: 
Quadro 1 - Características da auditoria externa

\begin{tabular}{|l|l|}
\hline Elementos & Auditoria Externa \\
\hline Sujeito & Profissional independente \\
\hline Aço e Objetivo & $\begin{array}{l}\text { Exame das demonstrações } \\
\text { financeiras }\end{array}$ \\
\hline Relatório Principal & Parecer \\
\hline Divisão de Independência & Mais vasto \\
\hline Interessados no trabalho & stakeholders \\
\hline Responsabilidade & Profissional, civil e criminal \\
\hline $\begin{array}{l}\text { Número de áreas cobertas pelo exame durante } \\
\text { um período }\end{array}$ & Maior \\
\hline $\begin{array}{l}\text { Intensidade do trabalho } \\
\text { Continuidade do trabalho }\end{array}$ & Menor \\
\hline
\end{tabular}

Fonte: Almeida (2014).

Sammour e Cintra (2019) evidenciam que em razão da Lei 6.704/76 da Sociedade Anônima, as empresas de capital aberto são obrigadas a contratar o serviço de auditoria externa, para que futuros investidores passem a ter confiança e segurança nas informações fornecidas pela entidade a fim de poderem investir nelas.

Enquanto isso, para Almeida (2014), a auditoria no setor financeiro compreende um processo objetivo e sistemático, que ocorre mediante a um terceiro independente, buscando a investigação e avaliação de evidências relacionadas às asserções sobre ações e ocorrências econômicas, com o objetivo de realizar a verificação de processos e ações, relatando os respectivos achados e dando o parecer às partes interessadas que fazem uso da informação financeira. Sendo que o auditor externo segue os padrões direcionados pelas Normas de auditoria independente. 


\subsubsection{NORMAS DA AUDITORIA INDEPENDENTE DA DEMONSTRAÇÃO CONTÁBIL (NBCT11)}

Segundo Ribeiro (2011), o Conselho Federal de Contabilidade aprovou por meio da Resolução CFC n 1958/2009, a NBC PA 03 - Revisão Externa de Qualidade pelos Pares, que foi revogada pela Resolução CFC n 1.323/11 que aprovou a NBC PA 11.

O auditor independente analisa e quantifica o grau de credibilidade das atividades e dos processos internos sem a obrigação de achar erros ou fraudes, mas se acha algum, ele tem o dever de emitir no parecer sugestões e direcionamentos para solucionar os problemas de acordo com as Normas da Auditoria Independente, conforme explanam Sammour e Cintra (2019) com base nos itens 11.1.4.3 e 11.1.4.4.

11.1.4.3 - ao detectar erros relevantes e quaisquer outras fraudes no decorrer dos seus trabalhos, o auditor tem obrigação de comunicar a administração da entidade e oferecer medidas corretivas, informando sobre possíveis efeitos no seu parecer, caso eles não sejam adotados.

11.1.4.4 - a responsabilidade primária na prevenção e detecção de fraudes e erros é administração da organização, através da prática de manter o adequado sistema contábil e de controle interno. Entretanto, o auditor deve planejar seu trabalho de forma a detectar fraudes e erros que impliquem efeitos relevantes nas demonstrações contábeis.

Já Ribeiro (2011) descreve que em 2009, o Conselho Federal de Contabilidade aprovou, por meio da Resolução n 1203, a Norma Brasileira de Contabilidade (NBC TA 200), que menciona Objetivos Gerais do Auditor Independente e da Condução da Auditoria, de acordo com as Normas de Auditoria, elaborada em consonância com a internacional ISA 200.

E em 2010, as novas normas de auditoria aprovadas pelo Conselho Federal de Contabilidade, iniciando pelas contidas na Resolução CFC n 1203/2009, tornaramse obrigatórias, dando embasamento ao profissional auditor. 


\subsubsection{PROFISSIONAL AUDITOR}

De acordo com Sammour e Cintra (2019), o papel do auditor externo é manter a independência, com isso, ele não pode ter nenhuma ligação empregatícia com a empresa onde irá desempenhar sua atividade como auditor, devendo seu parecer ser idôneo e livre de qualquer desconfiança.

Para isso, Almeida et al. (2019) afirmam que é necessário que os profissionais de auditoria independente possuam conhecimentos técnicos e específicos, e utilizem-os adequadamente, em aderência aos objetivos que se desejam alcançar. Assim, de forma geral, o conhecimento do auditor se baseia em matérias contábeis, econômicas, financeiras, administrativas e de controle.

De acordo com Almeida et al. (2019), essas características, aliadas à uma postura independente, são cruciais para garantir que os processos sejam verificados de forma imparcial, explorando todos os requerimentos e as normas necessárias que devem ser seguidos pela organização. Devido a essa independência, Leitão et al. (2018) afirmam que $o$ auditor externo examina e verifica as atividades desempenhadas pelo auditor externo e pelos demais setores, como o setor financeiro.

\subsection{DEPARTAMENTO FINANCEIRO}

O departamento financeiro exerce uma função chave nas organizações, pois é por meio deste que os recursos financeiros são geridos, garantindo que as operações do negócio sejam mantidas com estabilidade. $O$ departamento financeiro, a contabilidade e os seus processos, são fundamentais para garantir a adequada alocação dos recursos, bem como manter a conformidade nos processos e transações financeiras realizadas (SILVA, 2013).

Biscaro et al. (2020) conceituam que o controle financeiro é primordial nas operações realizadas pelo setor financeiro, pois é através de seus lançamentos e das suas operações que análises precisas sobre o capital da empresa são feitas. 
É através das informações financeiras que a contabilidade irá gerar seus relatórios e demonstrações contábeis. Nesse contexto, Ferreira (2016) afirma que a contabilidade é um instrumento essencial para a obtenção de resultados nas organizações por auxiliar os gestores nos controles, visando minimizar riscos e maximizar resultados em seus processos operacionais e de gestão. É importante que os profissionais contábeis estejam atentos sobre os instrumentos contábeis que podem ser utilizados com o intuito de melhorar a gestão das organizações, atendendo às necessidades dos usuários e auxiliando no processo de tomada de decisões.

Desta forma, Ferreira (2016) destaca que é necessário que as organizações procurem instrumentos e meios que as auxiliem a identificar pontos de melhoria em seus negócios, de forma que estas garantam a otimização de seus recursos, agregando o máximo de valor possível ao produto ou serviço que é colocado no mercado para atender seus clientes, consumidores e investidores.

Um destes instrumentos é a auditoria externa e os controles internos, visto que por meio destes é possível controlar e mitigar a probabilidade de erros e fraudes nos processos financeiros das organizações.

\subsubsection{CONTROLE INTERNO FINANCEIRO}

Após implementar um negócio, os gestores devem estar cientes da necessidade do controle contínuo dos principais indicadores, bem como o controle sobre os demais fatores que podem gerar risco para a realização das atividades da empresa. Conforme Do Nascimento et al. (2020), o controle interno possui relação direta com o crescimento acelerado das atividades econômicas empresariais, uma vez que contribui de forma eficiente para execução das atividades e possibilita a elaboração de estratégias de negócios.

Nesse contexto, Ferreira (2016) cita que o controle interno diz respeito aos métodos e instrumentos utilizados para resguardar e tornar padrão, e com exatidão todas as informações processadas no setor financeiro, ou em qualquer outro setor da instituição. Nesta lógica, o controle interno é visto como uma alternativa essencial para 
afirmar se os recursos da organização estão sendo corretamente utilizados, e se os números reportados nas demonstrações financeiras estão influenciando a realidade do negócio (RIBEIRO, 2011). Ele também conceitua que o controle interno também pode aumentar a eficácia das tarefas por meio da diminuição de custos ou de tempo demandado para a realização das mesmas. É por meio do controle interno e da apuração dos resultados obtidos que é possível avaliar e desafiar as estratégias e políticas adotadas e, assim, propor melhorias para a gestão, a fim de obter resultados vantajosos para o negócio.

Em face da importância do controle interno para as organizações, muitas empresas passaram a fazer uso das auditorias como forma de avaliar suas atividades e identificar riscos em atuações que vão contra os requisitos previamente definidos, seja pela legislação, pelos manuais profissionais específicos, ou de acordo com os requerimentos de processos e conduta estabelecidos por cada organização (RIBEIRO, 2011).

Sendo assim, o departamento financeiro representa um dos setores em que o controle interno é fundamental. Essa área é incumbida por processos importantes como contratos, controles de contas a pagar, contas a receber, conciliações contábeis e bancárias e contabilidade de custos.

De acordo com Silva (2013), a gestão financeira de um negócio tem relação com o planejamento, análise e controle de fundos financeiros, que podem ser oriundos de diferentes fontes no mercado. A gestão financeira e seus controles são essenciais, pois, por meio deste acompanhamento é possível criar ações e alternativas que corroborem para o aumento do patrimônio da empresa.

Os processos dos departamentos financeiros podem gerar muitos riscos regulatórios, legais e de reputação caso venham a falhar, caso haja fraudes, erros, ou caso não atendam corretamente os requisitos necessários. E perante esse cenário é de suma importância definir todos os processos de contas a pagar e a receber. 


\subsubsection{CONTROLE DE CONTAS A PAGAR}

Os processos de contas a pagar se referem às obrigações da empresa, que podem ser de curto, médio ou longo prazo, e referem-se às obrigações da empresa com terceiros, que ocorre por via de compra de mercadoria ou prestação de serviços. Posto isso, os dados devem ser fidedignos, visto que descrevem a saída de recursos da empresa. Desta forma, é essencial o controle, principalmente, com relação ao pagamento realizado aos fornecedores, mediante análises sobre como é feito o controle interno e se este atende as normas necessárias (SILVA, 2013).

Conforme Biscaro et al. (2020), ter crédito perante os fornecedores é de suma importância. O controle de contas a pagar é o protagonista da situação, pois através de suas operações os pagamentos devem ser mantidos em dia, sem atrasos, devendo os registros serem lançados de forma clara e limpa.

É através das contas a pagar que, segundo Silva (2013), o controle interno se torna adequado para uma gestão hábil, para que haja uma análise das melhores oportunidades de uso dos recursos ou critérios e prioridades ao assumir novos compromissos. Sendo assim, o autor estabeleceu um fluxograma de rotina de trabalho para esse setor: 
Figura 1 - Controle de contas a pagar

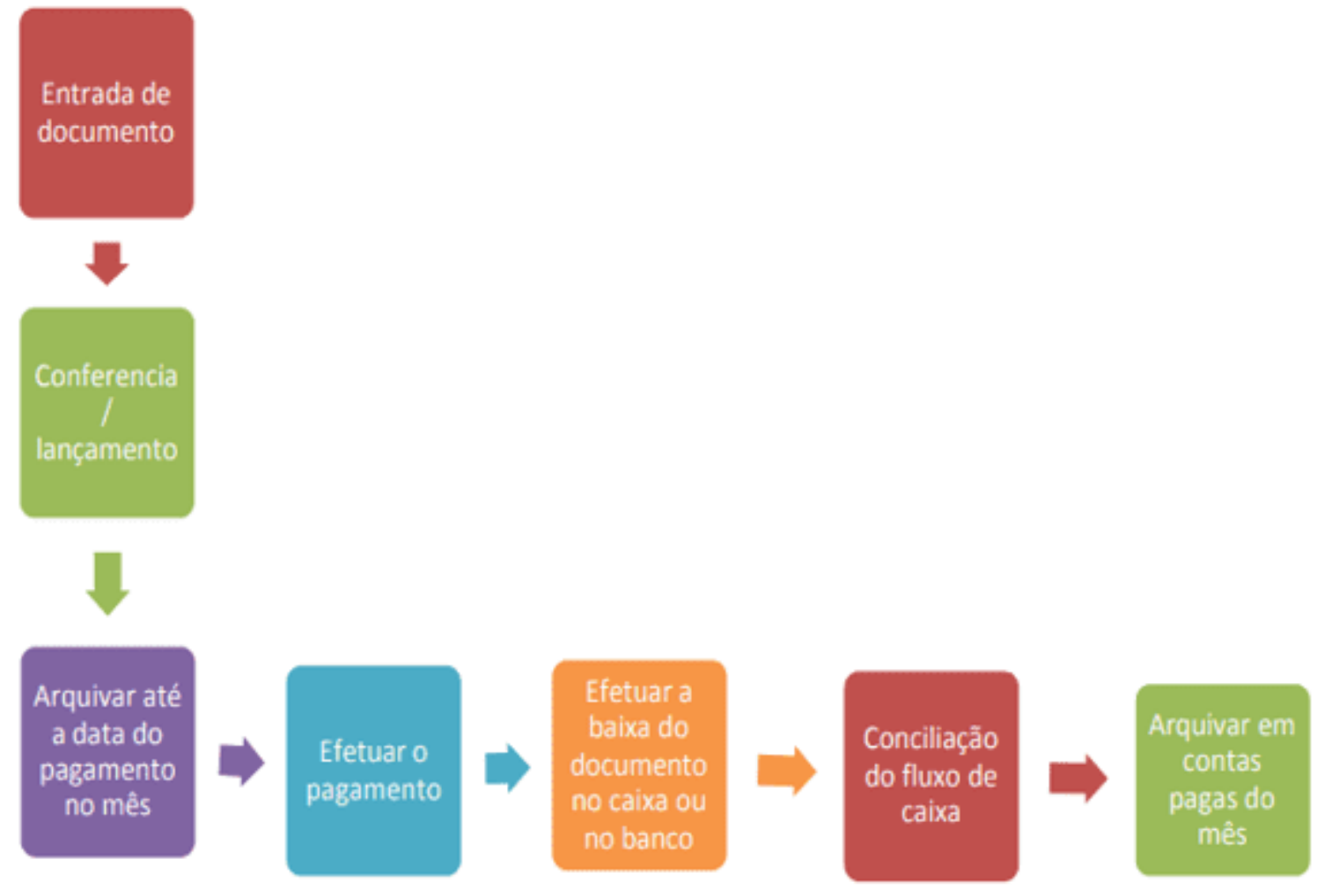

Fonte: Silva, 2013, p. 24.

Sendo assim, Crepaldi (2000 apud BISCARO et al., 2020) afirma que a empresa estará segura, tendo a certeza de que nenhuma conta foi inventada, que todo pagamento é realmente da empresa e foi devidamente autorizado, assim como todas as compras, e que esses processos foram devidamente registrados.

\subsubsection{CONTROLE DE CONTAS A RECEBER}

Contas a receber são processos ligados ao ingresso de recursos na empresa, que ocorre por intermédio da venda de mercadoria ou de serviço, e podem ser de curto, médio ou longo prazo. Segundo De Assis et al. (2019), as contas a receber geram as referências necessárias e primordiais para a tomada de decisão, pois é através deste ativo que os gestores irão conduzir e direcionar os futuros passos da instituição. A gestão eficiente das contas a receber proporciona fluxo de caixa satisfatório e um bom controle interno. Esses dois resultados proporcionam maior segurança à empresa 
quanto ao recebimento de valores (SILVA, 2013). O autor apresenta abaixo um exemplo de fluxograma de controle de contas a receber nas empresas:

Figura 2 - Controle de contas a receber

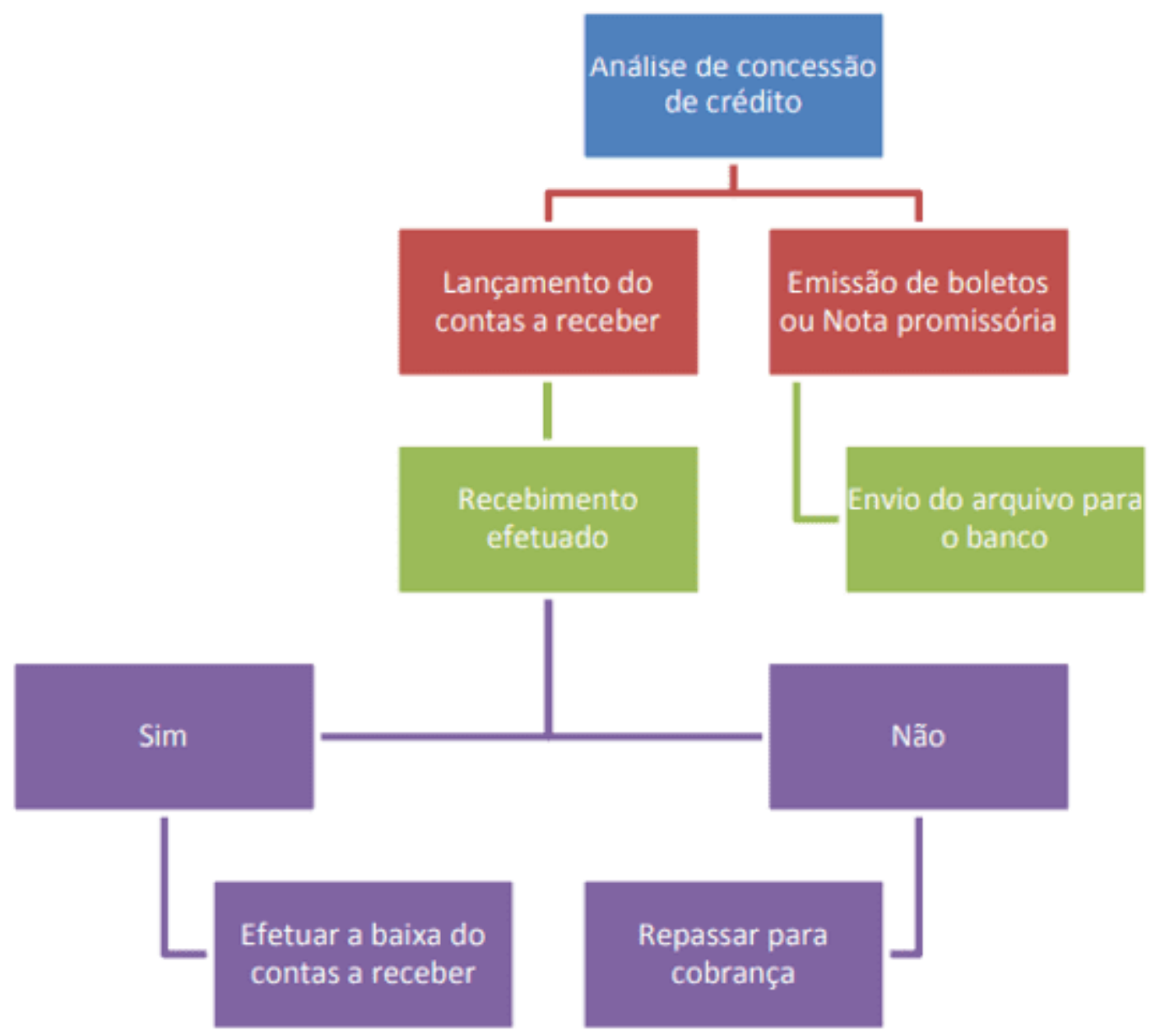

Fonte: Silva, 2013, p. 25.

Biscaro et al. (2020) afirmam que o contas a receber direciona a organização, pois através dela é possível gerar relatórios que possivelmente serão utilizados para gerar dados para o provisionamento de futuros ativos, dando a gestão empresarial a oportunidade de planejar seus próximos passos e aquisições de bens.

Devido a isso, Silva (2013) destaca que a gestão das contas a receber é fundamental para mitigar altos níveis de inadimplência para a empresa. Caso o nível de inadimplentes esteja descontrolado, a empresa pode enfrentar problemas em seu 
fluxo de caixa, ocasionando endividamento. Desta maneira, é essencial um sistema de controle para redução desse risco ao mínimo. Esse controle deve ser feito de forma periódica, de preferência mensalmente, por meio da conferência de duplicatas em atraso, análise financeira de clientes e definindo ações e estratégias para resolução dos desafios destes processos (SILVA, 2013).

\subsubsection{CONCILIAÇÃO BANCÁRIA}

Biscaro et al. (2020) destacam que hoje em dia é impossível uma entidade não ter conta bancária, e ter controle bancário é essencial nesse mundo corporativo. Ele evidencia a importância do controle bancário através dos registros de débito e crédito, ressaltando o objetivo do controle bancário que são:

a) confrontação dos registros da empresa e os lançamentos gerados pelo banco, além de apurar as diferenças nos registros se isso ocorrer:

b) gerar informações sobre os saldos bancários existentes, inclusive se são suficientes para pagar os compromissos do dia.

O excesso de confiança dos gestores, aliado a muitos empregados com acesso a informações e transações críticas nos sistemas gerenciais, colocam o negócio em risco, e muitas vezes pode provocar situações constrangedoras para ambas as partes, como por exemplo, erros e fraudes. Desta forma, é essencial implantar o processo da auditoria, uma vez que por meio da conferência dos extratos bancários é possível identificar os sinais de melhorias e verificar se os processos bancários estão sendo realizados da forma correta (CAMPOS et al. 2018).

De acordo com Ribeiro et al. (2020), a auditoria é importante para o setor financeiro por gerar informações que servirão de suporte e direcionamento para futuras decisões gerenciais, o que tornará a contabilidade mais precisa aos usuários.

Para Campos et al. (2018), ao auditar a conta no Banco, o auditor, solicita o extrato bancário, providenciando uma carta de autorização para solicitação direta e, realiza as devidas conferências, que são relevantes para investigar o processo e elaborar o parecer. 
Nesse momento, o auditor, por meio dos extratos bancários, realiza a auditoria da conta do Banco, realizando a conferência de todas as transações e lançamentos bancários e apresenta à empresa o parecer técnico com considerações referentes aos procedimentos e avaliações realizadas, o que de acordo com Campos et al. (2018) é ponto fundamental em uma auditoria no setor financeiro.

\subsection{BALANÇO FINANCEIRO X BALANÇO CONTÁBIL}

Segundo Nascimento et al. (2011), o Balanço Financeiro aponta os créditos e os débitos realizados com as receitas e despesas dos recursos financeiros, é através deste balanço que o gestor pode realizar seu planejamento de fluxo de caixa, e assim decidir seus próximos passos na administração da empresa.

Como cita Silva (2013), a Lei 6.404/76 da Sociedades Anônimas diz que o Balanço Financeiro tem como objetivo buscar e verificar entradas e saídas para apuração dos recursos disponíveis. Já o Balanço Contábil ou Balanço Patrimonial é uma demonstração financeira e patrimonial impreterível para as empresas de grande porte, pois, como Nascimento et al. (2011) referenciam, o Balanço Patrimonial não só demonstra como se qualifica os bens da empresa de forma quantitativa como também qualitativamente, sendo o diferencial entre os dois balanços.

\subsection{AUDITORIA NO DEPARTAMENTO FINANCEIRO}

No departamento financeiro de uma organização vários tipos de auditoria podem ser aplicáveis, no entanto, as mais comuns são: gestão, fiscal, tesouraria e riscos. Do Amaral e Bertegani (2018) descrevem sobre esses tipos específicos de auditoria em que:

A Auditoria Contábil e Financeira objetiva garantir a autenticidade das demonstrações financeiras do negócio, por artifício de procedimentos, controles e princípios contábeis.

A Auditoria Operacional objetiva melhorar a eficiência dos sistemas operacionais e identificar possibilidades de redução de custos, por meio da avaliação de aderência aos objetivos traçados, além da verificação dos controles e procedimentos aplicados. 
A Auditoria Fiscal visa assegurar que os controles internos são eficientes para bom relacionamento entre fisco e o contribuinte, por meio da otimização na aplicação da legislação fiscal e mitigação de riscos envolvendo passivos tributários, trabalhistas e previdenciários.

A Auditoria de Gestão tem foco maior em planejamento e processo de tomada de decisão, embasada na auditoria operacional.

A Auditoria de Qualidade é primordial para assegurar maior qualidade dos produtos e serviços. Para que isto aconteça é essencial que o profissional auditor interno siga os princípios profissionais, que se baseiam em integridade, objetividade, confidencialidade $\mathrm{e}$ competência.

Juliani (2018) enfatiza que a auditoria no setor financeiro é de grande importância, é através dela que é conferido o real saldo e os registros utilizados pela empresa, garantindo que o recurso esteja sendo utilizado de forma correta, dando credibilidade às operações realizadas e geradas no setor.

Já Moraes (2013) diz que a auditoria tem o intuito de coletar, tabular e transformar todos os dados em relatórios com informações precisas sobre o setor financeiro, autenticando ou dando sugestões de melhoria para os processos, principalmente se houve achados de erros ou fraudes.

Estes tipos de auditoria, quando realizados de forma satisfatória, onde as empresas estão interessadas em colocar em prática e melhorar todas as mudanças decorrentes dos achados do auditor, podem proporcionar diversas vantagens para a melhoria dos processos e gestão financeira, automatizando a funcionalidade do departamento e diminuindo os riscos de erros ou fraudes.

\subsubsection{ANÁlise DE CONTROLE INTERNOS E RELATÓRIOS FINANCEIROS}

A gestão do negócio demanda um robusto sistema de controle interno para garantir um ambiente de conformidade, processos simplificados, avaliação de riscos, atividades de controle, processos de informação e comunicação e um monitoramento de funções e processos (DO NASCIMENTO et al., 2020). Segundo os autores, a análise de controles e relatórios financeiros internos por parte da auditoria 
independente é fundamental para auxiliar nos pontos de aperfeiçoamento e assegurar que os controles vigentes são suficientes para garantir a segurança dos processos e operações da empresa.

Moraes (2013) relata que o controle interno deve ser utilizado com o intuito de garantir que seus recursos estão sendo aplicados de forma correta, através de seus procedimentos já pré-estabelecidos, conciliados à geração de relatórios financeiros que irão resguardar e proteger os ativos da organização.

Assim, como Ribeiro et al. (2020) afirmam, é através dessa análise que podemos chegar à conclusão de que a relação do controle interno e a geração dos relatórios financeiros são importantes para que a auditoria externa seja realizada de forma correta e adequada, a fim de alcançar um parecer mais fidedigno da real situação financeira da empresa.

\subsubsection{PARECER DA AUDITORIA}

Mendes de Luca et al. (2010) ressaltam que o foco de uma auditoria externa é o parecer, cujo é o resultado concreto e impresso dos dados coletados sobre os processos praticados nas organizações auditadas.

O que Do Amaral e Bertegani (2018) reafirmam ao dizer que o parecer é a opinião final do auditor que, por sua vez, deve ser baseado em fatos concretos e possíveis de serem comprovados, através dos papéis de trabalho, documentação relevante e análise de fatos com total imparcialidade e independência.

Nesse contexto, Mota e Martins (2018) citam a norma NBC - TA 701 do Conselho Federal de Contabilidade que destaca que o auditor independente deve determinar os assuntos de auditoria, após opinião formada sobre os resultados das demonstrações contábeis, devendo comunicar suas recomendações por processo de relatório (parecer) da auditoria nas organizações auditadas.

Podendo os achados pelo auditor serem emitidos em diferentes formas de parecer como Mendes de Luca et al. (2010), exemplificam. 
O parecer limpo (sem ressalva, ou parecer-padrão) configura-se em um atestado de que as normas e práticas contábeis foram plenamente observadas na preparação das demonstrações contábeis, é a opinião expressa pelo auditor quando ele conclui que as demonstrações contábeis são elaboradas, em todos os aspectos relevantes, de acordo com os requisitos da estrutura de relatório financeiro aplicável.

O parecer com ressalva deve ser emitido quando o auditor, tendo obtido evidência de auditoria apropriada e suficiente, conclui que as distorções, individualmente ou em conjunto, são relevantes, mas não generalizadas nas demonstrações contábeis; ou ele não consegue obter evidência apropriada e suficiente de auditoria para suportar sua opinião, mas ele conclui que os possíveis efeitos de distorções não detectadas, se houver, sobre as demonstrações contábeis poderiam ser relevantes, mas não generalizados.

O parecer adverso deve ser emitido quando, tendo obtido evidência de auditoria apropriada e suficiente, o auditor conclui que as distorções, individualmente ou em conjunto, são relevantes e generalizadas para as demonstrações contábeis.

O parecer abstenção deve ser emitido pelo auditor quando não puder expressar uma opinião, em circunstâncias raras, envolvendo diversas incertezas.

Além disso, o trabalho executado pelo auditor externo independente segue um cronograma de trabalho estruturado. As principais características deste formato de auditoria são demonstradas a seguir:

Quadro 2 - Características do trabalho executado por auditores externos

\section{Objetivo Principal}

Enunciar parecer sobre as demonstrações financeiras

2. Destinatários

Stakeholders

3. Âmbito

Recai sobre as demonstrações financeiras

4. Realização

Por profissionais de entidade independente, que não ligados a entidade $x$ auditada

5. Metodologia 
Destaque na análise e emissão de parecer sobre as demonstrações $x$ financeiras obrigatória

Estudo por sondagem nos registros contábeis

Embasado nos parâmetros a comparação dos padrões já pré-existentes $x$ Investiga e contrapõe seu trabalho embasado em torno do balanço e $x$ demonstração de resultados

6. Normas de Referência

Normas e princípios da contabilidade em conformidade

7. Frequência

Periódica, a princípio anualmente

8. Independência

Em relação à unidade empresarial

Fonte: Adaptado de Almeida (2014).

A auditoria externa tem uma concepção universal das atividades, por isso o seu parecer é essencial para o fortalecimento e robustez da empresa frente ao mercado.

\subsubsection{DESAFIOS ENCONTRADOS NA AUDITORIA EXTERNA NO SETOR FINANCEIRO}

Assis et al. (2014) conceituam que o auditor está cada vez mais tendo um papel de grande importância no mundo corporativo. A procura pelo serviço de auditoria externa tem aumentado substancialmente. E com essa procura surgem os desafios.

Juliani (2018) afirma que algumas dificuldades ocorrem no meio externo, onde a empresa não tem processos, pela falta de controle sobre suas atividades, cabendo, portanto, ao auditor mapear todas as atividades realizadas no setor financeiro.

Nesse contexto, Biscaro et al. (2020) descrevem que sem a implementação de um processo bem estruturado, a empresa perde o controle de seus ativos, e conscientizar gestores que estão acostumados a essa forma é o maior dos desafios. 
Sammour e Cintra (2019) enfatizam que o auditor externo enfrenta grandes problemas para entender as demonstrações nas empresas auditadas. Sendo assim, saber se a empresa está organizada de acordo com os princípios contábeis, é fundamental para que $o$ auditor possa emitir seu parecer idôneo sem nenhum problema.

\subsubsection{BENEFÍCIOS FUTUROS DA AUDITORIA EXTERNA NO SETOR FINANCEIRO}

Biscaro et al. (2020) apontam que os gestores devem começar a entender e a valorizar a auditoria externa, além dos benefícios agregados que ela proporciona às organizações, como clareza em suas operações, levando aos futuros investidores confiança e credibilidade, e assegurando o emprego adequado dos ativos da empresa.

Como Sammour e Cintra (2019) relatam, a auditoria não tem o intuito de interferir na gestão empresarial, e sim mostrar melhorias futuras e novos direcionamentos no processo, através do parecer emitido pelo auditor, agregando, desta maneira, mais informações que deverão ser codificadas em resultados positivos.

Juliani (2018) enfatiza que a auditoria agrega confiança e segurança para o setor financeiro, onde os gestores terão uma visão futura de seus ativos e seus investimentos através do fluxo de caixa, otimizando a tomada de decisão.

Enfim, a auditoria externa só tende a adicionar melhorias funcionais ao setor financeiro, atestando sua credibilidade e transparência aos processos, e auxiliando na correção dos erros ou fraudes encontradas.

\section{MATERIAIS E MÉTODOS}

Esta seção apresenta os materiais e métodos desta pesquisa, que se refere às características metodológicas da pesquisa, além dos recursos e fontes que foram utilizados para realizá-la. De acordo com Martins e Theóphilo (2016), a metodologia é utilizada para fazer referência a uma disciplina e seu objeto, identificando tanto o 
estudo dos métodos, quanto os métodos empregados por uma dada ciência. Os métodos são os caminhos para alcançar o objetivo da pesquisa.

\subsection{PROCEDIMENTOS METODOLÓGICOS}

Como metodologia de trabalho, este artigo utiliza a revisão bibliográfica sistemática, pois trata-se de uma revisão que objetiva responder a uma pergunta específica, por meio da utilização de métodos explícitos e sistemáticos.

\subsubsection{QUANTO À NATUREZA}

Haja vista a competitividade dos mercados, os gestores estão em constante busca por ferramentas e soluções para melhorar a gestão financeira de seus negócios. Miguel (2015) destaca algumas etapas necessárias para realizar uma gestão empresarial de sucesso, e destaca os seguintes pontos necessários: (a) entender o projeto em que você deseja investir; (b) obter uma melhor compreensão do negócio por intermédio de cursos profissionalizantes; (c) distribuir o valor do investimento estimado; e (d) avaliar os custos fixos e variáveis da instituição. Entretanto, após implementar um negócio os gestores devem estar cientes da necessidade de controle e avaliação contínua dos resultados do negócio, a fim de mitigar riscos que possam comprometer as operações da empresa.

Neste sentido, a auditoria externa pode ser vista como ferramenta essencial para melhorar a gestão financeira das empresas. Desta forma, por instrumento da pesquisa bibliográfica sistemática, este artigo propõe identificar os principais ,empresas. Para realizar a revisão sistemática algumas etapas precisam ser seguidas, como: elaboração da pergunta, circunscrição dos estudos, compreensão dos dados e aperfeiçoamento e upgrade da revisão. Desta maneira, a revisão sistemática parte de uma questão de pesquisa específica, cuja fonte de seleção é baseada em critérios aplicados uniformemente, seguida de avaliação criteriosa e reprodutível, e é frequentemente baseada em resultados de pesquisa clínica (BOTELHO et al., 2011). 


\subsubsection{QUANTO AOS FINS}

A pesquisa se caracteriza como exploratória, visto que busca explorar e discutir sobre os principais estudos envolvendo esta temática. Segundo Martins e Theóphilo (2016), a investigação exploratória ocorre na área de conhecimento onde há escasso conhecimento acumulado e sistematizado.

Desta maneira, esta pesquisa se fundamenta na exploração de respostas para a seguinte questão norteadora: De que forma a auditoria externa pode proporcionar melhorias na gestão financeira empresarial? Neste contexto, o objetivo desta pesquisa é elencar as principais vantagens obtidas por meio da auditoria externa como ferramenta de gestão financeira nas empresas.

\subsubsection{QUANTO AOS MEIOS}

Quanto aos meios desta metodologia, por se tratar de uma pesquisa bibliográfica sistemática, a pesquisa se baseia na busca por bibliografias sobre o tema. A pesquisa bibliográfica, segundo Martins e Theóphilo (2016), é um meio de formação científica para análise teórica e é considerada como parte indispensável de qualquer trabalho científico, pois visa a edificação da base teórica do estudo. Porém, na pesquisa bibliográfica sistemática, ocorre a busca de conteúdos da temática utilizando seleções, fontes e critérios previamente definidos. Conforme Botelho et al. (2011), está se baseia na integração de opiniões, conceitos ou ideias oriundas das pesquisas utilizadas no método.

\section{CONSIDERAÇÕES FINAIS}

Para garantir o atendimento dos requisitos necessários para as operações, e evitar riscos e fraudes nos processos, a auditoria externa surgiu como uma ferramenta essencial para o enriquecimento da gestão financeira nas empresas. Os processos de auditoria passaram a auxiliar as organizações como um todo no alcance dos objetivos estratégicos, na gestão de riscos e suporte à imagem dos negócios no mercado. 
Diante dos estudos utilizados nesta pesquisa de referência bibliográfica é conclusivo que a auditoria externa tem um papel essencial no mercado competitivo das grandes empresas. Podendo passar credibilidade e confiança aos investidores e a todas as partes interessadas que passam a ter uma outra visão a respeito da empresa.

Os objetivos desta pesquisa consistem em analisar a relação dos benefícios da auditoria externa e o desenvolvimento das atividades do setor financeiro; descrever os métodos e instrumentos utilizados pelo auditor externo no desenvolvimento de suas atividades; analisar a relação da auditoria como método preventivo para setor financeiro; e apontar o resultado e o impacto da auditoria externa no setor financeiro.

A questão norteadora do artigo remete à discussão: Quais os benefícios da auditoria externa para o funcionamento do setor financeiro? Nota-se que a questão norteadora foi respondida considerando os benefícios apresentados, que dizem respeito a eliminação da falta de transparência e confiabilidade, os quais representam os principais pontos para que organizações não consigam crescer e se manter. É nesse ponto que entra em foco o setor financeiro, que é considerado o coração das empresas. Assim, evidencia-se que a auditoria externa é uma investigação para verificar ou analisar determinados setores e suas atividades desenvolvidas.

Conclui-se que a auditoria externa, ao examinar, analisar, corrigir e certificar as demonstrações contábeis e financeiras de uma empresa, torna-se uma ferramenta de gestão de melhoria indispensável ao setor financeiro, para controlar as atividades de uma organização. Tendo a preocupação em elevar grau de confiança nas demonstrações por parte de seus usuários, dificultando assim possíveis desvios ou fraudes. Assim, ela fornece uma confirmação de sua saúde financeira, para possíveis investimentos.

Desta forma, espera-se que esta pesquisa possa servir de inspiração para estudos futuros e que mais empresas façam uso da auditoria externa, pois assim poderão usufruir de processos mais eficientes e confiáveis, gerando valores para a organização como um todo. 


\section{REFERÊNCIAS}

ALMEIDA, B. J. M. Manual de Auditoria Financeira: Uma análise integrada baseada no risco. Lisboa: Escolar Editora, 2014.

ALMEIDA, S. R. V. et al. Responsabilidade do auditor independente na detecção de fraudes: A visão da sociedade. REASU-Revista Eletrônica de Administração da Universidade Santa Úrsula, v. 3, n. 2, 2019.

ASSIS, E.T. et al. e desafios do perfil do auditor externo: Um estudo de caso. SEGeT - XI Simpósio de excelência em gestão e tecnologia, 2014. Disponível em: https://www.aedb.br/seget/arquivos/artigos14/702050.pdf. Acesso em: 10 de Out. de 2021.

BISCARO, E. T. et al. Controles internos: a contribuição da controladoria e da auditoria no setor financeiro das empresas. Revista de extensão e iniciação científica da Unisociesc, 7(1), 33-71, 2020. Disponível em: http://reis.unisociesc.com.br/index.php/reis/article/view/74. Acesso em: 16 de Out. de 2021.

BOTELHO, L. L. R. et al. O método da revisão integrativa nos estudos organizacionais. Gestão e Sociedade, v. 5, n. 11, p. 121-136, 2011.

CAMPOS, L. M. B. et al. Auditoria interna nas contas bancárias de uma organização. XII Jornada Científica das Faculdades Integradas de Bauru - FIB, 2018.

CARVALHO, A. V. Auditoria e gestão da informação e do conhecimento: interações e perspectivas teórico-práticas. Ciência da Informação, v. 48, n. 2, 2019.

DE ASSIS, D. M. et al. Controle das contas a pagar e receber de um pequeno negócio: estudo de caso de uma escola de idiomas. Cafi, v. 2, n. 1, 2019. p. 112128. 
DO AMARAL, L. S. S; BERTEGANI, M. C. A importância da Auditoria Interna nas Organizações. Revista Terra \& Cultura: Cadernos de Ensino e Pesquisa, v. 33, n. 65, p. $45-58,2018$.

DO NASCIMENTO, J. P. S. et al. O controle interno nas microempresas e empresas de pequeno porte. Revista Expressão Católica, v. 9, n. 1, 2020.

FERREIRA, C. M. M. Auditoria financeira e auditoria interna: cooperação e criação de valor. Universidade do Minho Escola de Economia e Gestão, 2016.

JULIANI, C. O. A Contribuição dos Controles Internos na execução de uma auditoria no setor financeiro: 0 caso de uma cooperativa. ljuí: Unijui. 2018. Disponível em: http://bibliodigital.unijui.edu.br:8080/xmlui/handle/123456789/5143. Acesso em: 17 de Out. de 2021.

LEITÃO, M. dos S. et al. Auditoria Interna x Auditoria Externa. Augusto Guzzo Revista Acadêmica, São Paulo, v. 1, n. 22, p. 203-220, 2018. ISSN 2316-3852. Disponível em: <http://www.fics.edu.br/index.php/augusto_guzzo/article/view/818>. Acesso em: 16 de Out. de 2021.

MARTINS, G. A.; TEÓPHILO, C. R. Metodologia da investigação científica para ciências sociais aplicadas. 3 ed. São Paulo: Atlas, 2016.

MENDES DE LUCA, M. M. et al. Os Mecanismos de Auditoria Evidenciados pelas Empresas Listadas nos Níveis Diferenciados de Governança Corporativa e no Novo Mercado da Bovespa. Contabilidade Vista \& Revista, [S. I.], v. 21, n. 1, p. 101130, 2010.

Disponível

em:

https://revistas.face.ufmg.br/index.php/contabilidadevistaerevista/article/view/817. Acesso em: 17 de out. de 2021.

MIGUEL, E. C. Avaliação do sistema de controle interno: estudo de caso em uma empresa de médio porte. Universidade federal de minas gerais faculdade de ciências econômicas, 2015. Disponível em: https://repositorio.ufmg.br/handle/1843/BUBDA3JF6V. Acesso em: 24 de ago. de 2021. 
MORAES, J. M. Auditoria interna aplicada nos setores financeiro e patrimonial em um hospital. Pato Branco: Universidade Tecnologia Federal do Paraná, 2013. Disponível em: http://repositorio.roca.utfpr.edu.br/jspui/handle/1/2290. Acesso em: 17 de Out. de 2021.

MOTA, P. R.; MARTINS, V. F. Novo relatório do auditor independente: uma análise dos principais assuntos de auditoria evidenciados nas empresas do setor aéreo brasileiro. RAGC, v. 6, n. 25, 2018.

NASCIMENTO, H. H. V. et al. Convergência às Normas Internacionais de Contabilidade Governamental: Análise e Comparação das Estruturas das Normas Brasileiras Atuais e Propostas. Recife: RIC - Revista da Informação Contábil. v. $5, \quad n^{\circ} \quad 2$ 2, p. 211-42. 2011. Disponível em: https://periodicos.ufpe.br/revistas/ricontabeis/article/view/7926. Acesso em: 17 de Out. de 2021.

RIBEIRO, B. B. et al. Prevenção de Fraude: Pontos de Controle na Auditoria das Conciliações Bancárias. Presidente Prudente: Etic, v. 16, n 16, 2020. Disponível em: file://C:/Users/ketelim/Downloads/8562-67654692-1-PB.pdf. Acesso em: 17 de Out. de 2021.

RIBEIRO, O. M.; RIBEIRO, J. M. Auditoria Fácil. São Paulo: Saraiva, 2011.

SAMMOUR, J. R.; CINTRA, D. G. B. Auditoria externa $\mathbf{x}$ interna: Funções e Diferenças. Revista De Estudos Interdisciplinares Do Vale Do Araguaia REIVA, 2(02), 14, 2019. Recuperado de http://reiva.unifaj.edu.br/reiva/article/view/85. Acesso em: 16 de Out. de 2021.

SILVA, K. F. M. Análise de controle interno: estudo de caso no contas a pagar e receber das empresas Visaluz e Escola Shekinah. Universidade Tecnológica Federal do Paraná, Pato Branco, 2013.

SOUSA, A. S. et al. A pesquisa bibliográfica: princípios e fundamentos. Cadernos da Fucamp, v. 20. n. 43, p. 64-83, 2021. 
Enviado: Outubro, 2021.

Aprovado: Novembro, 2021. 